\title{
Molecular characterization of Babesia vogeli in dogs from Belém, northern Brazil
}

P.H.G. Moraes' ${ }^{1}$, C.P. Rufino', A.R.F. Baraúna', T. Reis' ${ }^{1}$, L.T.D. Agnol', A.M.C. Meneses ${ }^{2}$, D.C.F. Aguiar ${ }^{1}$, M.R.T. Nunes ${ }^{3}$ and E.C. Gonçalves ${ }^{1,3}$

${ }^{1}$ Laboratório de Tecnologia Biomolecular, Instituto de Ciências Biológicas, Universidade Federal do Pará, Cidade Universitária, Belém, PA, Brasil ${ }^{2}$ Instituto da Saúde e Produção Animal, Universidade Federal Rural da Amazônia, Montese, Belém, PA, Brasil

${ }^{3}$ Centro de Inovações Tecnológicas, Instituto Evandro Chagas, Levilândia, Ananindeua, PA, Brasil

Corresponding author: P.H.G. Moraes

E-mail: pablogmoraes@gmail.com

Genet. Mol. Res. 14 (4): 16364-16371 (2015)

Received August 9, 2015

Accepted October 23, 2015

Published December 9, 2015

DOI http://dx.doi.org/10.4238/2015.December.9.4

ABSTRACT. Babesiosis is an infectious hemolytic disease that occurs world wide, and is caused by a protozoan of the Babesia genus (Apicomplexa). Little is known about this genus; therefore, this study conducted a molecular characterization of Babesia spp in naturally infected dogs in northern Brazil. Blood samples were collected from 172 dogs from metropolitan Belém, and screened for Babesia spp using semi-nested polymerase chain reactions. Subsequently, 18S rDNA gene fragments were amplified and sequenced. Alignments of the 27 nucleotide sequences returned fragments measuring $1023 \mathrm{bp}$ in size, which did not include any polymorphic sites (100\% identity). This genotype was very similar to the $18 \mathrm{~S}$ rDNA gene in $B$. vogeli. This study provides an important molecular characterization of the parasite responsible for canine babesiosis in naturally infected dogs in metropolitan Belém. In addition, the $18 \mathrm{~S}$ rDNA gene in $B$. vogeli may represent the most common genotype occurring in South America.

Key words: Babesia vogeli; Canine babesiosis; Molecular characterization; Northern Brazil 


\section{INTRODUCTION}

Babesiosis, or piroplasmosis, is an infectious hemolytic disease that occurs worldwide, and is caused by a protozoan in the order Piroplasmida (Apicomplexa), which utilizes a variety of tick species as natural vectors (Lobetti, 1998; Boozer and Macintire, 2003; Passos et al., 2005). In addition to causing significant economic losses in the livestock industry, babesiosis causes clinical manifestations in companion animals and humans (Boozer and Macintire, 2003; Adaszek and Winiarczyk, 2008; Irwin, 2010).

Due to the wide range of vertebrate hosts susceptible to infection by tick-transmitted apicomplexan parasites, babesiosis is a disease of great economic, veterinary, and clinical importance, and a major research effort has been exerted in understanding its mechanisms of pathogenicity and drug resistance, and to find a vaccine (Schnittger et al., 2012).

Four protozoan species, Babesia canis, Babesia vogeli, Babesia rossi, and Babesia gibsoni, are known to cause canine babesiosis worldwide. The first three species are recognized by their vector (tick) species, virulence, and geographic distributions. B. canis is transmitted by Dermacentor reticulatus, a tick species found in Europe (Boozer and Macintire, 2003), while the vector of $B$. vogeli is the red tick, Rhipicephalus sanguineus, which is found in the United States and in tropical and subtropical regions around the world, including Brazil (Passos et al., 2005). B. rossi is the most virulent and is transmitted by Haemaphysalis spp, a tick found in Africa (Lobetti, 1998). B. gibsoni is transmitted by Haemaphysalis longicornis and R. sanguineus (Uilenberg, 2006).

In Brazil, canine babesiosis is typically caused by $B$. vogeli, which is known to occur in the south (Trapp et al., 2006; Jojima et al., 2008; Vieira et al., 2013), southeast (Dell-Porto et al., 1990, 1993; Spiewak, 1992; O’Dwyer, 2000; Costa-Junior et al., 2009; Lemos et al., 2012), midwest (Souza et al., 2004; Duarte et al., 2011; Spolidorio et al., 2011), north-east (Carlos et al., 2006; Lima et al., 2006; Ramos et al., 2010; Silva et al., 2012), and north (Spolidorio et al., 2013; Moraes et al., 2014). In addition, there have been some reports of $B$. gibsoni from the south of the country (Trapp et al., 2006; Jojima et al., 2008).

Regarding canine piroplasms occurring in northern Brazil, their molecular characterization is limited to that conducted by Moraes et al. (2014), who reported a short fragment (394 bp) of the 18S rDNA gene from $B$. vogeli in one dog from the Belém metropolitan area, Pará State. Molecular methods have been used for the description of genotypically novel pathogens by their small subunit rRNA (ssrRNA) gene sequences, which have been applied for the comparison of geographically different strains. Therefore, the present study was conducted to characterize Babesia spp. in naturally infected dogs in Belém.

\section{MATERIAL AND METHODS}

\section{Samples and DNA extraction}

A total of 172 samples were randomly selected from dogs with clinical signs of hemoparasites infection that were treated at the Veterinary Hospital of the Universidade Federal Rural da Amazônia (HOVET-UFRA), Belém, Pará State between August and October 2011. The blood samples were drawn into tubes containing ethylenediaminetetraacetic acid (EDTA).

Total DNA of each sample was extracted from a $300-\mu \mathrm{L}$ aliquot of the blood by using a 
standard phenol-chloroform procedure, as described by Sambrook et al. (1989). DNA quality was checked by electrophoresis on an agarose gel, and the DNA was then quantified using a Qubit ${ }^{\circledR}$ fluorometer (Invitrogen).

\section{Polymerase chain reaction (PCR) amplification and DNA sequencing}

The molecular detection of Babesia spp was performed in a semi-nested PCR (snPCR), as described by Moraes et al. (2014). Briefly, a primer set targeting a partial sequence (394 bp) of the $18 \mathrm{~S}$ rDNA gene was used in an initial reaction. A second primer set was then used to amplify an internal fragment (208 bp). The PCRs included a positive control, which was the DNA of a peripheral blood sample from one dog (also treated at HOVET-UFRA) that exhibited large intraerythrocytic piroplasms that were morphologically compatible with Babesia vogeli, which was examined by light microscopy after panoptic staining. Sterile, twice-distilled water was used as a negative control.

Positive samples (according to the SnPCR) were characterized based on partial small subunit rDNA (ssrDNA) sequence analysis. In addition, two overlapping fragments were amplified using the following primer sets: i) Babf-f/Babesia common (Kordick et al., 1999; Martin et al., 2006), which amplified a 394-bp fragment at the 5' end; and ii) RIB-24/RIB-21 (Zahler et al., 2000), which amplified an 834-bp fragment at the 3 ' end.

All of the PCR products were visualized after electrophoresis on $1.5 \%$ agarose gel in a Tris acetate-EDTA (TAE) buffer, using GelRed ${ }^{\text {Tw }}$ Nucleic Acid stain (Biotium) and an ultraviolet transilluminator (E-BOX VX2, Vilber Lourmat). A 100-bp molecular marker (Invitrogen ${ }^{\text {Tw }}$ DNA ladder, Life Technologies) was used to estimate the size of each amplified fragment.

The amplicons obtained were purified using a GFX PCR DNA and Gel Band Purification kit (GE Healthcare) and ligated to a $\mathrm{pGEM}^{\circledR}-\mathrm{T}$ vector plasmid (Promega), which were then inserted into TOP 10 Escherichia coli (Invitrogen ${ }^{\text {TM }}$, Life Technologies). Cloned fragments were obtained by PCR from the recombinant clones of the colonies using the M13F/M13R primers, and were automatically sequenced in a 3500xL Genetic Analyzer (Applied Biosystems), following the manufacturer protocol.

\section{Sequence analysis}

BioEdit software (Hall, 1999) was used to assemble the forward and reverse sequences obtained. In order to investigate the occurrence of different genotypes, we generated a database that included, in comparison to the sequences we obtained, all similar sequences of Babesia spp. from Brazilian dogs that are currently available in GenBank (accession no.: AY371194-AY371196, DQ469736-DQ469737, EF052623-EF052633, EF636702, EU436750, EU436752, GQ214514, GU386266-GU386282, JF295087, JN36808, KC688693, KC989959, KF753247, and KF970926KF970929). We also included sequences of $B$. vogeli strains from Venezuela (DQ297390), USA (AY371198), China (HM590440), Japan (AB083374), Spain (DQ439545), France (AY072925), Taiwan (HQ148663), Romania (HQ662635), and Egypt (AY371197).

\section{Phylogenetic analysis}

We performed a phylogenetic analysis using the neighbor-joining method in MEGA6 software, using the Kimura-2 parameter (Tamura et al., 2013). Bootstrap consensus was inferred 
from 1000 replicates. The $18 \mathrm{~S}$ rDNA gene sequence of Plasmodium falciparum (GenBank accession No. M19172) was used as an outgroup. MUSCLE software (Edgar, 2004) was used to align and trim the sequences, in order to obtain equal lengths.

\section{RESULTS}

\section{Molecular detection of Babesia spp.}

The specific $18 \mathrm{~S}$ rDNA gene fragment of Babesia spp. was detected in approximately $15.7 \%(27 / 172)$ of the canine blood samples we analyzed. Alignments of the nucleotide sequences returned 1023-bp fragments (excluding primers), which did not exhibit any polymorphic sites, i.e., they exhibited $100 \%$ identity similarity to each other. A BLASTN search (http://blast.ncbi.nlm.nih. gov/Blast.cgi) of this unique sequence (GenBank accession number KT333456) revealed a high similarity to the $18 \mathrm{~S}$ rDNA gene in $B$. vogeli.

Although the database we generated included sequences ranging from 235 to $1608 \mathrm{bp}$ long (data not shown), a comparison of 75 sequences ( 27 from this study and 48 retrieved from GenBank) allowed us to generate a consensus sequence that was highly similar to the 18S rDNA gene in $B$. vogeli from elsewhere (Table 1). No polymorphic sites were observed among the 1023 bp of the 18S rDNA gene of $B$. vogeli from Belém and Minas Gerais in Brazil, or from Venezuela, China, or Japan.

\begin{tabular}{|c|c|c|c|c|c|c|c|c|c|c|c|c|c|c|c|c|c|}
\hline \multirow[t]{4}{*}{ Strain } & \multirow[t]{4}{*}{ Reference } & \multirow[t]{4}{*}{ GenBank accession No. } & \multirow[t]{4}{*}{ Identity (\%) ${ }^{\mathrm{a}}$} & \multicolumn{14}{|c|}{ Nucleotide position ${ }^{b}$} \\
\hline & & & & & 3 & 3 & 4 & 5 & 5 & 5 & 7 & 7 & 7 & 8 & 8 & 8 & \\
\hline & & & & 4 & 7 & 8 & 0 & 1 & 5 & 8 & 3 & 5 & 7 & 2 & 2 & 7 & 3 \\
\hline & & & & 4 & 7 & 0 & 7 & 8 & 1 & 8 & 0 & 9 & 7 & 4 & 6 & 7 & 1 \\
\hline Belém & Present study & - & - & $\mathrm{T}$ & A & $\mathrm{T}$ & A & $\mathrm{T}$ & $\mathrm{T}$ & $\mathrm{T}$ & T & A & A & A & $\mathrm{C}$ & $\mathrm{T}$ & $\mathrm{T}$ \\
\hline Brazil & Passos et al. (2005) & AY371196 & 100 & . & . & . & . & . & . & . & . & . & . & . & . & . & . \\
\hline Venezuela & Rey-Valeirón et al. (2007) & DQ297390 & 100 & . & . & . & & . & . & . & . & . & . & . & . & . & . \\
\hline U.S.A. & Passos et al. (2005) & AY371198 & 99.9 & . & . & . & $\mathrm{C}$ & . & . & . & . & . & . & . & . & . & . \\
\hline China & Unpublished & HM590440 & 100 & . & . & . & . & . & . & . & . & . & . & . & . & . & . \\
\hline Japan & Arai et al. (1998) & AB083374 & 100 & . & . & . & . & . & . & . & . & . & . & . & . & . & . \\
\hline Spain & Criado-Fornelio et al. (2003) & DQ439545 & 99.4 & . & . & . & $\mathrm{C}$ & . & . & A & . & G & G & . & $\mathrm{T}$ & $A$ & . \\
\hline France & Caccio et al. (2002) & AY072925 & 99.9 & . & . & . & $\mathrm{C}$ & . & . & . & . & . & . & . & . & . & . \\
\hline Taiwan & Unpublished & HQ148663 & 99.4 & C & G & C & & & . & . & C & . & . & G & . & . & C \\
\hline Romania & Unpublished & HQ662635 & 99.8 & . & . & . & & C & C & . & . & . & . & . & . & . & . \\
\hline Egypt & Passos et al. (2005) & AY371197 & 99.8 & . & . & . & & C & C & . & . & . & . & . & . & . & \\
\hline
\end{tabular}

a Values are percentages of nucleotide sequence identities for $1023 \mathrm{bp}$, determined by pairwise alignment. ${ }^{\mathrm{b}} \mathrm{Dots}$ (.) and letters indicate conserved nucleotides and substitutions, respectively.

\section{Phylogenetic analysis}

All of the sequences were trimmed to the same length (1023 bp), and the results confirmed the close phylogenetic relationships between worldwide $B$. vogeli, which clustered in a branch that was closely related to $B$. canis (Figure 1). A close relationship between $B$. vogeli strains from Venezuela, China, and Japan, in comparison to the Brazilian B. vogeli strain, was also found. 


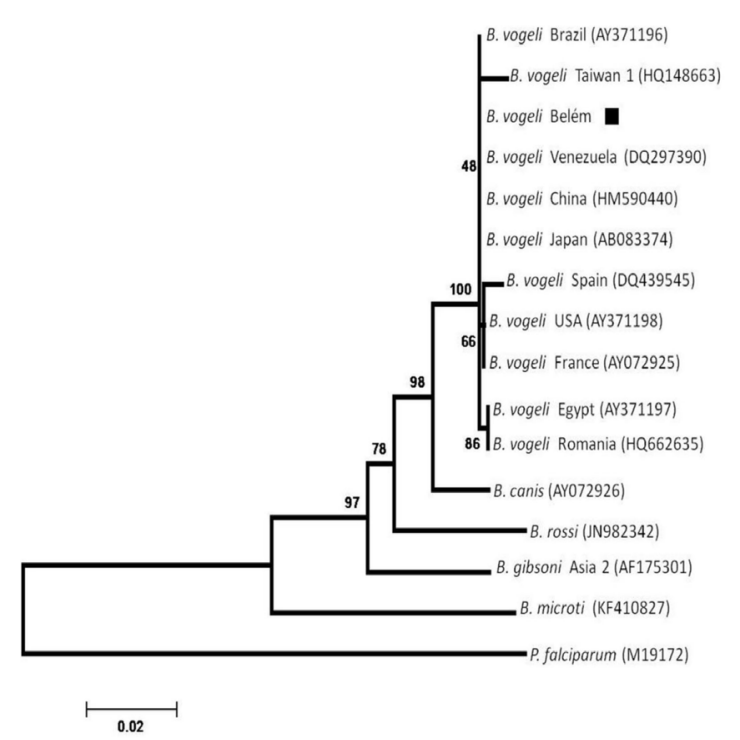

Figure 1. Phylogenetic tree based on Babesia 18S rDNA. Sequences were compared using the neighbor-joining method with a distance matrix calculation with Kimura-2 parameters in MEGA6 software, using Plasmodium falciparum as the outgroup. The scale bar indicates the number of mutations per sequence position. The numbers at the nodes represent the percentages of 1000 bootstrap re-samplings.

\section{DISCUSSION}

The molecular method we used allowed for the detection of four protozoan species ( $B$. canis, B. vogeli, B. rossi, and B. gibsoni), which are known to cause canine babesiosis worldwide, and revealed the presence of $B$. vogeli in dogs from Belém.

Despite the fact that several studies have been conducted on Babesia spp., those by Spolidorio et al. (2013) and Moraes et al. (2014) appear to be the only published reports of the occurrence of the genus in northern Brazil. Spolidorio et al. (2013) conducted a serosurvey and an indirect immunofluorescence assay with the antigens B. vogeli, Ehrlichia canis, and six Rickettsia species, while Moraes et al. (2014) used the same molecular method as used in the present study. Whereas Spolidorio et al. (2013) detected anti-B. vogeli antibodies in $59.6 \%$ of urban dogs in Santarém, Pará State and in $29.1 \%$ of rural dogs, Moraes et al. (2014) reported that only $22 \%$ $(22 / 100)$ of dogs tested positive for Babesia spp. DNA. The results of these two studies and of the present report suggest that $B$. vogeli is the most common, if not the only, species of Babesia in dogs east of the Amazon in northern Brazil.

Molecular phylogeny has made major contributions towards revealing evolutionary lineages and their relationships (Schnittger et al., 2012). The present study is, to the best of our knowledge, the first time that the molecular analysis of a large fragment of 18S rDNA gene sequence of $B$. vogeli from Belém has been conducted. Our results, i.e., the sequence alignments and phylogenetic tree, confirm those of previous studies (Passos et al., 2005; Duarte et al., 2011), which suggest, based on the $18 \mathrm{~S}$ rDNA sequences, that there is low genetic diversity among $B$. vogeli strains in Brazil.

Indeed, our analysis returned only one 18S rDNA genotype of $B$. vogeli occurring in Belém, which was identical to those from Minas Gerais, Brazil (Passos et al., 2005) and Venezuela (Rey- 
Valeiron et al., 2007). It is noteworthy that the genotype obtained here was the fourth-largest $18 \mathrm{~S}$ rRNA gene fragment of $B$. vogeli ever obtained in Brazil.

Duarte et al. (2011), based on a short B. vogeli 18S rDNA gene fragment from Goiânia, Goiás (mid-west Brazil), identified two genotypes: GO 1 and GO 4, which differed by one substitution (A to $\mathrm{G}$ ) at position 128 of their alignment. GO 1 was $100 \%$ identical to three sequences from Minas Gerais, Brazil, as well as to the sequences from Belém obtained in the present study.

Most Brazilian studies that have characterized the 18S rDNA gene sequences of $B$. vogeli have been based on the direct sequencing of enzymatically amplified DNA, which has a higher error rate than sequencing based on molecular cloning (Clark and Whittman, 1992). Further evidence of sequencing errors in the database we generated is that most nucleotide differences (indels and/or substitutions) were located at the ends of the sequences. In addition, some nucleotide sequences were not curated before submission to GenBank. For example, in the sequence KC989959 (not published), the first 183 of the 584 nucleotides did not clearly align with any other 18S rDNA gene sequences of Babesia. Therefore, we cannot conclusively state that only one $B$. vogeli strain is in Brazil. However, based on the genetic similarities that we observed, we suggest that the $B$. vogeli 18S rDNA genotype detected in dogs from Belém may represent the most common one on the South American continent.

Based on partial ssrRNA sequences, Carret et al. (1999) questioned the phylogenetic position of $B$. vogeli; however, the findings of the present study are similar to those obtained by Passos et al. (2005), who reported $100 \%$ homology between B. vogeli from Brazil, Venezuela, Japan, and China. B. vogeli is transmitted by the red (brown) dog tick ( $R$. sanguineus), which is found in tropical and subtropical regions (Irwin, 2010). Genetic similarities between the B. vogeli described here and isolates from tropical (Venezuela) and subtropical (Japan) regions suggest that the development, establishment, and permanence of the same vectors and pathogens was possible, because there are similar climatic conditions between these countries and northern Brazil.

Based on vector specificity, pathogenicity, and morphology, it has been assumed that $B$. vogeli causes almost all cases of babesiosis in Brazil (Passos et al., 2005), and only recently have a few cases of infection by $B$. gibsoni been detected in dogs from southeast Brazil (Trapp et al., 2006). However, there have been no studies conducted on the characterization of Babesia species in dogs in northern Brazil. Therefore, this study provides an important molecular characterization of the protozoan parasite responsible for canine babesiosis in naturally infected dogs in northern Brazil.

The high genetic homology demonstrated here between $B$. vogeli isolates, even on different continents (ranging from 99.4 to 100\%), corroborates the results of Passos et al. (2005), who found that these protozoa belong to the same taxonomic entity. The question of whether small sequence variations between $B$. vogeli isolates affect the virulence of the parasite remains unanswered, and requires further study.

\section{Conflicts of interest}

The authors declare no conflict of interest.

\section{ACKNOWLEDGMENTS}

We are grateful to FAPESPA (\#ICAAF 012/2012) for financial support, and to CAPES, CNPQ, and PROEX/UFPA for scholarships to P. Moraes, C.P. Rufino, A.R. Baraúna, L.D. Agnol, and T. Reis. 


\section{REFERENCES}

Adaszek L and Winiarczyk S (2008). Molecular characterization of Babesia canis canis isolates from naturally infected dogs in Poland. Vet. Parasitol. 152: 235-241.

Boozer AL and Macintire DK (2003). Canine babesiosis. Vet. Clin. Small Anim. 33: 885-904.

Carlos RSA, Paranhos EB, Bezerra RA, Pellizzoni SG, et al. (2006). Prevalência de Babesia canis em cães do município de Ilhéus e Itabuna, Bahia. In: Programa \& Resumos do XIV Congresso Brasileiro de Parasitologia Veterinária e II Simpósio Latinoamericano de Riquetsioses, São Paulo, 335.

Carret C, Walas F, Carcy B, Grande N, et al. (1999). Babesia canis canis, Babesia canis vogeli, Babesia canis rossi: differentiation of the three subspecies by a restriction fragment length polymorphism analysis on amplified small subunit ribosomal RNA genes. J. Euk. Microbiol. 46: 298-303.

Clark AG and Whittam TS (1992). Sequencing errors and molecular evolutionary analysis. Mol. Biol. Evol. 9: 744-752.

Costa-Júnior LM, Ribeiro MFB, Rembeck K, Rabelo EML, et al. (2009). Factors associated with seroprevalence of canine babesiosis caused by Babesia vogeli in rural areas of the State of Minas Gerais. Res. Vet. Sci. 86: 257-260.

Dell-Porto A, Oliveira MR and Miguel O (1990). Babesia canis em cães de rua da cidade de São Paulo. Estudo comparativo de métodos de diagnóstico. Braz. J. Vet. Res. Anim. Sci. 27: 41-45.

Dell-Porto A, Oliveira MR and Miguel O (1993). Babesia canis in stray dogs from the city of São Paulo. Comparative studies between the clinical and hematological aspects and the indirect fluorescence antibody test. Rev. Bras. Parasitol. Vet. 2: 37-40.

Duarte SC, Parente JA, Pereira M, Soares CMA, et al. (2011). Phylogenetic characterization of Babesia canis vogeli in dogs in the state of Goiás, Brazil. Rev. Bras. Parasitol. Vet. 4: 274-280.

Edgar RC (2004). MUSCLE: a multiple sequence alignment method with reduced time and space complexity. BMC Bioinformatics 5: 113.

Hall TA (1999). BioEdit: a user-friendly biological sequence alignment editor and analysis program for Windows 95/98/NT. Nucleic Acids Symp. Ser. 41: 95-98.

Irwin PJ (2010). Canine babesiosis. Vet. Clin. Small Anim. 6: 1141-1156.

Jojima FS, Garcia JL, Vidotto MC, Balarin MRS, et al. (2008). Occurrence and molecular characterization of Babesia species in a canine hospital population in the Londrina Region, Parana State, Brazil. Rev. Bras. Parasitol. Vet. 17: 277-283.

Kordick SK, Breitschwerdt EB, Hegarty BC, Southwick KL, et al. (1999). Coinfection with multiple tick-borne pathogens in a walker hound kennel in North Carolina. J. Clin. Microbiol. 37: 2631-2638.

Lemos DL, Cerqueira AMF, Toma HK, Silva AV, et al. (2012). Detection and molecular characterization of piroplasms species from naturally infected dogs in southeast Brazil. Rev. Bras. Parasitol. Vet. 2: 137-142.

Lima MM, Lima AMA, Farias MPO, Ferreira DRA, et al. (2006). Frequencia de hematozoários em cães atendidos no hospital veterinário do departamento de Medicina Veterinária da Universidade Federal Rural de Pernambuco (HV/DMV-UFRPE) no período de 2004-2005. In: Programa \& Resumos do XIV Congresso Brasileiro de Parasitologia Veterinária e II Simpósio Latinoamericano de Riquetsioses, São Paulo, 328.

Lobetti RG (1998). Canine babesiosis. Comp. Cont. Educ. Vet. Pract. 4: 418-431.

Martin AR, Dunstan RH, Roberts TK and Brown GK (2006). Babesia canis vogeli: a novel PCR for its detection in dogs in Australia. Exp. Parasitol. 112: 63-65.

Moraes PHG, Aguiar DCF, Rufino CP, Meneses AMC, et al. (2014). Optimization of a molecular method for the diagnosis of canine babesiosis. Rev. Bras. Parasitol. Vet. 1: 105-108.

O' Dwyer LHO (2000). Diagnóstico de hemoparasitas e carrapatos de cães provenientes de áreas rurais em três mesorregiões do estado do Rio de Janeiro, Brasil. Doctoral thesis, Instituto de Biologia, Universidade Federal do Rio de Janeiro, Rio de Janeiro.

Passos LMF, Geiger SM, Ribeiro MF, Pfister K, et al. (2005). First molecular detection of Babesia vogeli in dogs from Brazil. Vet. Parasitol. 1: 81-85.

Ramos R, Ramos C, Araújo F, Oliveira R, et al. (2010). Molecular survey and genetic characterization of tick-borne pathogens in dogs in metropolitan Recife (north-eastern Brazil). Parasitol. Res. 107: 1115-1120.

Rey-Valeirón C, Criado-Fornelio A, Zavala E and Granados R (2007). Parasitological and molecular characterization of a Venezuelan isolate of Babesia canis. Rev. Cient. Maracaibo. 1: 21-27.

Sambrook J, Fritsch EF and Maniatis T (1989). Molecular cloning. A laboratory manual. Cold Spring Harbor Laboratory Press, Cold Spring Harbor.

Schnittger L, Rodriguez AE, Florin-Christensen M and Morrison DA (2012). Babesia: a world emerging. Infect. Genet. Evol. 12: $1788-1809$.

Silva AB, Costa AP, de Sá JC, Costa FB, et al. (2012). Molecular detection of Babesia canis vogeli in dogs and in Rhipicephalus sanguineus from the middle-west region of Maranhão, northeast Brazil. Cienc. Anim. Bras. 3: 388-395. 
Souza Al, Dagnone AS and Machado RZ (2004). Infecção por Anaplasma platys em cães de Campo Grande-MS. Rev. Bras. Parasitol. Vet. 13: 352.

Spiewak G (1992). Aspectos epidemiológicos, clínicos e de diagnóstico da infecção por Babesia canis em cães atendidos em clínicas veterinárias em Belo Horizonte. Master's thesis, Universidade Federal de Minas Gerais.

Spolidorio MG, Minervino AHH, Valadas SYOB, Soares HS, et al. (2013). Serosurvey for tick-borne diseases in dogs from the Eastern Amazon, Brazil. Rev. Bras. Parasitol. Vet. 2: 214-219.

Spolidorio MG, Torres MM, Campos WN, Melo AL, et al. (2011). Molecular detection of Hepatozoon canis and Babesia canis vogeli in domestic dogs from Cuiabá, Brazil. Rev. Bras. Parasitol. Vet. 20: 253-255.

Tamura K, Stecher G, Peterson D, Filipski A, et al. (2013). MEGA6: Molecular evolutionary genetics analysis, version 6.0. Mol. Biol. Evol. 30: 2725-2729

Trapp SM, Messick JB, Vidotto O, Jojima FS, et al. (2006). Babesia gibsoni genotype Asia in dogs from Brazil. Vet. Parasitol. 141: $177-180$.

Uilenberg G (2006). Babesia - a historical overview. Vet. Parasitol. 138: 3-10.

Vieira TSWJ, Vieira RFC, Nascimento DAG, Tamekuni K, et al. (2013). Serosurvey of tick-borne pathogens in dogs from urban and rural areas from Paraná State, Brazil. Rev. Bras. Parasitol. Vet. 1: 104-109.

Zahler M, Rinder H, Zweygarth E, Fukata T, et al. (2000). Babesia gibsoni of dogs from North America and Asia belong to different species. Parasitology 120: 365-369. 